\title{
Metabolic Control in Patients with Type 2 Diabetes Mellitus in a Public Hospital in Peru: A cross- sectional study in a low- middle income country
}

\author{
Irma Elizabeth Huayanay-Espinoza ${ }^{\text {Corresp., }}{ }^{1}$ ， Felix Guerra-Castañon ${ }^{1}$ ， María Lazo-Porras ${ }^{1,2}$, Ana Castaneda- \\ Guarderas ${ }^{1,2,3,4}$, Nimmy Josephine Thomas ${ }^{5}$, Ana-Lucia Garcia-Guarniz ${ }^{1}$, Augusto A Valdivia-Bustamante ${ }^{1}$, \\ German Malaga Rodriguez ${ }^{1,2,6,7}$ \\ 1 Unidad de Conocimiento y Evidencia (CONEVID), Universidad Peruana Cayetano Heredia, Lima, Peru \\ 2 CRONICAS Centre of Excellence in Chronic Diseases, Universidad Peruana Cayetano Heredia, Lima, Peru \\ 3 Knowledge and Evaluation Research (KER) Unit, Mayo Clinic, Rochester, Minnesota, United States \\ 4 Emergency Medicine, Mayo Clinic, Rochester, Minnesota, United States \\ 5 Rollins School of Public Health, Emory University, Atlanta, Georgia, United States \\ 6 Faculty of Medicine “Alberto Hurtado", Universidad Peruana Cayetano Heredia, Lima, Peru \\ 7 Department of Internal Medicine, Hospital Cayetano Heredia, Lima, Peru \\ Corresponding Author: Irma Elizabeth Huayanay-Espinoza \\ Email address: irma.huayanay@upch.pe
}

Objective: The objective of this study was to assess patients' achievement of ADA (American Diabetes Association) guideline recommendations for glycosylated hemoglobin, lipid profile, and blood pressure in a type 2 diabetes mellitus (T2DM) outpatient clinic in a low-middle income country (LMIC) setting.

Methods: This is a descriptive cross-sectional study with 123 ambulatory T2DM patients who are being treated at a public hospital in Lima, Peru. Data was gathered via standardized interviews, clinical surveys, and anthropomorphic measurements for each patient. Blood samples were drawn in fasting state for measures of glucose, glycosylated hemoglobin (HbAlc), and lipid profile. Laboratory parameters and blood pressure were evaluated according to ADA recommendations.

Results: Of the 123 patients, 81 were women and the mean age was 61.8 years. Glycemic control was abnormal in 82 (68.33\%) participants, and 45 (37.50\%) were unable to control their blood pressure. Lipid profile was abnormal in 73 (60.83\%) participants. Only nine (7.50\%) participants fulfilled ADA recommendations for glycemic, blood pressure, and lipid control.

Conclusions: Amongst individuals with type 2 diabetes, there was poor attainment of the ADA recommendations (HbAlc, blood pressure and LDL-cholesterol) for ambulatory T2DM patients. Interventions are urgently needed in order to prevent long-term diabetic complications. 
1 Metabolic Control in Patients with Type 2 Diabetes Mellitus in a Public Hospital in Peru: A cross2 sectional study in a low-middle income country

4 Irma Elizabeth Huayanay-Espinoza ${ }^{1}$, Felix Guerra-Castañon ${ }^{1}$, María Lazo-Porras ${ }^{1,}{ }^{2}$, Ana Castaneda5 Guarderas ${ }^{1,2,3,4}$, Nimmy Josephine Thomas ${ }^{5}$, Ana-Lucia Garcia-Guarniz ${ }^{1}$, Augusto Valdivia Bustamante ${ }^{1}$, 6 German Malaga Rodriguez $z^{1,2,6,7}$

8 1. Unidad de Conocimiento y Evidencia (CONEVID), Universidad Peruana Cayetano Heredia, Lima, $9 \quad$ Perú

10 2. CRONICAS Center of Excellence in Chronic Diseases, Universidad Peruana Cayetano Heredia, Lima, 11 Perú

12 3. Knowledge and Evaluation Research (KER) Unit, Mayo Clinic, Rochester MN 55905.

13 4. Department of Emergency Medicine, Mayo Clinic, Rochester MN 55905.

14 5. Rollins School of Public Health, Emory University, Atlanta, Georgia

15 6. Faculty of Medicine "Alberto Hurtado", Universidad Peruana Cayetano Heredia, Lima, Perú

16 7. Department of Internal Medicine, Hospital Cayetano Heredia, Lima, Perú

17

30

\section{CORRESPONDING AUTHOR}

German Malaga MD, MSc.

Address: Calle Las cantutas 479, Casuarinas Sur, Surco 33. Lima, Perú

Email: german.malaga@upch.pe

Phone: +51992768300 


\section{$31 \quad \underline{\text { ABSTRACT }}$}

32 Objective: The objective of this study was to assess patients' achievement of ADA (American Diabetes

33 Association) guideline recommendations for glycosylated hemoglobin, lipid profile, and blood pressure in a type 2

34 diabetes mellitus (T2DM) outpatient clinic in a low-middle income country (LMIC) setting.

35 Methods: This is a descriptive cross-sectional study with 123 ambulatory T2DM patients who are being treated at a 36 public hospital in Lima, Peru. Data was gathered via standardized interviews, clinical surveys, and anthropomorphic 37 measurements for each patient. Blood samples were drawn in fasting state for measures of glucose, glycosylated 38 hemoglobin $(\mathrm{HbA} 1 \mathrm{c})$, and lipid profile. Laboratory parameters and blood pressure were evaluated according to 39 ADA recommendations.

40 Results: Of the 123 patients, 81 were women and the mean age was 61.8 years. Glycemic control was abnormal in $4182(68.33 \%)$ participants, and $45(37.50 \%)$ were unable to control their blood pressure. Lipid profile was abnormal 42 in $73(60.83 \%)$ participants. Only nine (7.50\%) participants fulfilled ADA recommendations for glycemic, blood 43 pressure, and lipid control.

44 Conclusions: Amongst individuals with type 2 diabetes, there was poor attainment of the ADA recommendations 45 (HbA1c, blood pressure and LDL-cholesterol) for ambulatory T2DM patients. Interventions are urgently needed in 46 order to prevent long-term diabetic complications.

47 


\section{Introduction}

52 Type 2 Diabetes Mellitus (T2DM) is a chronic disease with a growing prevalence worldwide [1, 2]. In 2014, the 53 International Diabetes Federation (IDF) estimated that the disease prevalence in South/Central America and Peru 54 was $8 \%$ and $6.1 \%$, respectively [2]. However, Seclen et al. found a slightly higher national prevalence of $7 \%$ in Peru 55 and $8.4 \%$ in metropolitan Lima - a prevalence that has almost doubled in the last seven years [3].

56 Metabolic control in T2DM is a critical component in diabetes care. Without well-established metabolic control, 57 complications can arise increasing mortality rates and lowering quality of life - this represents an important burden of disease for low-middle income countries (LMICs) [2, 4]. Additionally, several comorbidities are related to poor metabolic control including dyslipidemia, hypertension, and obesity, increasing the risk of long-term macro and micro-vascular complications [5]. It has been reported that more than $80 \%$ of deaths associated with T2DM in LMICs occur due to poor metabolic control [6]. A multicenter study performed in the US comparing glycemic control in Hispanic/Latino, non-Hispanic white, and non-Hispanic black populations found that the non-Hispanic black and white populations had better glycemic control when compared to their Hispanic/Latino counterparts [7]. They reported that Hispanic/Latino populations had the lowest percentage of participants with good glycemic control among the three groups, $47.3 \%$ compared to $52.9 \%$ and $52.6 \%$ in non-Hispanic white and black populations, respectively. In another multicenter cross-sectional study conducted in nine countries in Latin America [8], the overall poor glycemic control (HbA1c $\geq 7 \%(53 \mathrm{mmol} / \mathrm{mol})$ ) was $56.8 \%$ while Peru had the worst numbers among all with 70\% having poor glycemic control. Another study conducted within an elderly population in Costa Rica reported that $37 \%$ had poor metabolic control $(\mathrm{HbAlc} \geq 7 \%(53 \mathrm{mmol} / \mathrm{mol})), 78 \%$ had a systolic blood pressure $\geq 130$ $\mathrm{mmHg}, 66 \%$ had a diastolic blood pressure $\geq 80 \mathrm{mmHg}$, and $78 \%$ had a LDL-cholesterol $\geq 100 \mathrm{mg} / \mathrm{dl}$ [9]. to evaluate the quality of T2DM management, it has been widely agreed that the proper management and control of glycosylated hemoglobin (HbA1c), LDL-cholesterol and blood pressure are the key to prevent complications [10]. These can also be used to measure the quality of diabetic healthcare in different health systems [10]. Moreover, it is well-known that factors associated with a healthy lifestyle [11], regular physical activity (three times a week), and adherence to treatment can positively influence the course of the disease [10]. There are several factors such as ethnicity and depression that have not been completely explored. With regards to depression, some studies have found a 15-20\% correlation between T2DM and depression incidence, although a significant association has not yet been found [12-14].

In South America, particularly in Peru, there are few studies that evaluate demographic and clinical characteristics associated with glycemic control, blood pressure, and lipid profile in a clinical setting [14]. Such a study could help to identify the main factors that affect the course of T2DM, thus letting physicians and patients work on modifying strategies to improve the patient's prognosis. 
86 choices, and clinical parameters of patients in a public hospital in Peru have an impact on the quality of control of 87 T2DM. 


\section{Materials and methods}

\subsection{Study design and participants}

We conducted a cross-sectional study in which participants diagnosed with T2DM were recruited between March and July 2012 from the Endocrinology clinic of Hospital Cayetano Heredia in Lima, Peru. This is a university hospital located in San Martin de Porres, a low-income district north of the Peruvian capital [15].

The recruitment strategy was convenience sampling, with patients recruited while they were waiting for their routine clinical encounter. The inclusion criteria included a diagnosis of T2DM for more than 12 months from the recruitment day, $\geq 18$ years old, and at least one visit to the Endocrinology clinic in the previous year. Patients were excluded if they were diagnosed with secondary or gestational diabetes, chronic non-cardio-metabolic diseases (systemic lupus erythematous, rheumatoid arthritis, chronic obstructive pulmonary disease), or any mental illness or incapability. Patients who had presented with major complications of T2DM (stroke, coronary heart disease, hyperglycemic/hypoglycemic crisis, diabetic foot) in the previous year and those who had been hospitalized within the previous six months were also excluded due to the decline in social, physical and psychological functionality after these major complications and their added risk factors for mortality[16,17].

\subsection{Assessment and outcome measures}

The participants were assessed using a standardized interview and an evaluation of their medical records, using the International Physical Activity Questionnaire (IPAQ), the Scale of Adherence to Diabetes Mellitus Type 2 Treatment (Escala de Adherencia al Tratamiento de la Diabetes Mellitus tipo II - EATDM-III), and Center for Epidemiological Studies-Depression (CES-D) scale [18-20]. For laboratory measurements, a venous sample of 10cc was taken from the arm in the morning after a minimum 8 hour fast from which fasting glucose, glycosylated hemoglobin, and lipid profile were measured.

To define "poor metabolic control," the American Diabetes Association (ADA) recommendations were used: poor glycemic control (HbA1c $\geq 7 \%$ (53 mmol/mol)), poor controlled blood pressure (BP $\geq 140 / 90 \mathrm{mmHg}$ ), and poor controlled LDL-cholesterol (LDL $\geq 100 \mathrm{mg} / \mathrm{dL}$ ) [10]. Also, we include an additional analysis using HbA1c $\geq 8 \%$, because some studies have recommended individualized treatment for each patient and propose the use of a less stringent parameter $[10,18]$.

Demographic variables were also collected including gender, age ( $<65$ years old or $\geq 65$ years old), and marital status (in a couple: married, cohabiting, or single: not in a relationship, widowed, divorced). The clinical data collected included: years of disease (1-10 years or $\geq 10$ years); treatment (none, oral anti-diabetic, insulin, both); body mass index (BMI), and chronic diabetic complications defined as microvascular (retinopathy, nephropathy, and neuropathy) and macrovascular (coronary heart disease, stroke, and peripheral artery disease).

Participant's activity levels were assessed using the IPAQ with three categories: inactive, minimally active, and HEPA active (health enhancing physical activity) [19]. (Supplementary table S1) 
121 The scale used to measure adherence was EATDM-III, which has previously been used in Costa Rica [20]. This 122 scale has 7 categories including family support, communal organization, physical exercise, medical control, hygiene

123 and self-care, diet, and appreciation of the physical condition. The questionnaire has 55 questions and each one has a 124 score between 0 and 4 . The total obtained is divided by the maximum score points (220 points) and then multiplied 125 by $100 \%$. Scores near $100 \%$ signify more adherence [20].

126 Depression was evaluated using the CES-D. A score greater than or equal to 24 is considered positive for the 127 presence of depression. The scale was previously validated for the Peruvian population with a sensitivity of $91.4 \%$ 128 and specificity of $96.7 \%$ [21].

129 Sample size and calculation

130 The sample size of 123 participants was based on the DEAL study (Diabetes en America Latina) [8], using a 131 prevalence of poor glycemic control of 56.7\% with a confidence level of 95\% ( $\mathrm{Z}=1.96)$. Calculated power for 132 depression was $28 \%$ [22].

\subsection{Statistical analysis}

135 Statistical analyses were performed using Stata 12.0. Demographic variables (age, gender, marital status), clinical 136 criteria (disease duration, treatment, complications), lifestyle factors (IPAQ, EATDM-III), and comorbidity 137 (depression) variables were compared against glycosylated hemoglobin looking for significant associations. Chi138 square was used for comparison of qualitative variables and t-test for comparison of a quantitative vs qualitative 139 variable.

140 Multivariate models were generated using Poisson regression reporting prevalence ratios (PR) and 95\% Confidence 141 intervals (CI). Crude and adjusted analyses were performed for the three models generated to evaluate the 142 independent association between (i) glycemic control, (ii) blood pressure, and (iii) LDL-cholesterol with 143 demographic, clinical, lifestyle, and comorbidity variables.

\section{$144 \quad 2.4$ Ethics}

145 The study protocol was approved by the Ethical Review Board of the Universidad Peruana Cayetano Heredia and 146 Ethical Committee of Hospital Cayetano Heredia. Written informed consent was obtained from all patients. 


\section{3.}

148 The recruitment rate was $89.78 \%$ (123/137). Of the 123 patients participating in the study, blood samples were 149 received from 120 patients. Most participants $(65.85 \%)$ were female and the mean age was $61.84 \pm 11.10$. In 150 addition, majority of the patients (63.41\%) were in a relationship (i.e. married, living together). Mean HbA1c was $1518.2 \% \pm 2.19(66 \mathrm{mmol} / \mathrm{mol})$, mean LDL $(\mathrm{mg} / \mathrm{dL})$ was $107.61 \pm 39.66$ and mean blood pressure was $133.26 \pm 19.03$ / $15275.64 \pm 10.84 \mathrm{mmHg}$. The prevalence of uncontrolled HbA1c was $68.33 \%$, uncontrolled LDL-cholesterol was $15360.83 \%$, and uncontrolled blood pressure was $37.50 \%$. With regards to comorbidities, $37.40 \%$ had hypertension and $15433.33 \%$ had depression. Other characteristics of the population studied are shown in Table 1. Using a cutoff point of 155 HbA1c of 7\%, only $9(7.5 \%)$ patients met all the standards of the ADA recommendations for T2DM, but when a 156 cutoff point HbA1c of $8 \%$ was utilized, 17 patients met all standards $(14.2 \%)$.

157 The patients diagnosed with diabetes for 1-10 years had better glycemic control compared to those who had had a 158 diabetes diagnosis for $\geq 10$ years ( $42.37 \%$ vs. $21.31 \%, p=0.013$ ). Good glycemic control was present in $21.92 \%$ 159 patients younger than 65 years old and in $46.81 \%$ of those older than 65 years ( $\mathrm{p}=0.004)$. Those patients who were 160 not on pharmacological treatment had better glycemic control than the patients who required pharmacologic therapy 161 ( $\mathrm{p}<0.001)$. A detailed comparison between each variable and glycemic control is shown in Table 2.

162 In the adjusted model, a negative association with poor glycemic control (HbA1c $\geq 7 \%$ ) was found in patients who 163 were 65 years or older when compared to younger participants (PR=0.59; 95\% CI: 0.44-0.78) and with patients who 164 were in a relationship compared to single patients ( $\mathrm{PR}=0.74$; 95\% CI: 0.59-0.92). Also, a positive association with 165 poor glycemic control was found with more than 10 years of disease ( $\mathrm{PR}=1.43 ; 95 \%$ CI: 1.05-1.71), oral antidiabetic $166(\mathrm{OAD})$ use plus insulin treatment ( $\mathrm{PR}=2.57$; 95\% CI: 1.05-6.32), and minimal physical activity (PR=1.63, 95\% CI: 167 1.23-2.15) in the crude and adjusted model in comparison with their counterparts. BMI was included in the adjusted 168 Poisson regression model, but there was no association found with glycemic control, LDL-cholesterol, or blood 169 pressure. We did not find an association between LDL-cholesterol or blood pressure and demographic, clinical, 170 lifestyle (IPAQ, EATDM-III) and comorbidity variables (Table 3). 


\section{Discussion}

\subsection{Main findings and comparison with other studies}

174

175 Only $7.5 \%$ of the patients achieved the levels of glycemic control in T2DM recommended by the ADA 176 (glycosylated hemoglobin, LDL-cholesterol and blood pressure). In Latin America, a Colombian retrospective study 177 with a bigger sample size got a similar result of 6.9\% [23]. There are several differences between these two studies. 178 For example, all participants in the Colombian study were from the social security health program, suggesting they 179 had better access to care for controlling their blood glucose levels and follow up care compared to our patients. The 180 Colombian study also had a bigger sample size from a multicenter study with a follow-up period of one year [23]. In 181 a twin cross-sectional study performed in India with one hundred participants and three time points - baseline, three 182 months, and six months - HbAlc, blood pressure and LDL-cholesterol were evaluated [24]. Only one participant (1\%) achieved the ADA's guidelines at three months, but at six months this number increased to 3 participants achieving the recommended guidelines (3\%). Due to some characteristics of our population, mostly advanced age and comorbidities, we also considered another cutoff point of $\mathrm{HbA} 1 \mathrm{c} \leq 8 \%$ for controlled diabetes, which indicated an increase in controlled disease from $7.5 \%$ to $14.2 \%$. Even though there's an increase, it is still not enough for the achievement of ADA recommendations. Furthermore, $26.67 \%$ of patients had HbA1c $>9 \%$; this is untenable and incompatible with a good healthcare system and appropriate quality of attention to patients with diabetes.

Of all participants in this study, $68.33 \%$ had poor glycemic control, $37.50 \%$ had uncontrolled blood pressure and $60.83 \%$ had an abnormal lipid profile. These are worrisome results as achieving the ADA recommendations is pertinent in decreasing micro-vascular and macro-vascular complications and death in T2DM patients. This is shown in the Steno 2 study, which compared intensive treatment against conventional treatment in primary outcomes of T2DM patients [25]. The outcomes of this study were positive for intensive treatment having an overall-death hazard ratio of 0.54 (95\% CI: 0.32-0.89; $\mathrm{p}=0.02$ ), cardiovascular-death hazard ratio of 0.43 (95\% CI: $0.19-0.94 ; \mathrm{p}=0.04)$ and cardiovascular-events hazard ratio of 0.41 (95\% CI: $0.25-0.67 ; \mathrm{p}<0.001)$.

In a systematic review of 14 studies that involved 19 countries: $55.5 \%$ of subjects had $\mathrm{HbAlc}>7 \%$ ( $53 \mathrm{mmol} / \mathrm{mol})$, $64.8 \%$ of subjects had blood pressure $>130 / 80$, and $48.6 \%$ subjects had LDL-cholesterol $>100 \mathrm{mg} / \mathrm{dL}$ [24]. The difference with these studies is that they were mainly conducted in high-income countries (17 out of 19 were high income countries) [26]. In the cross-sectional study in India, they measured HbA1c, blood pressure and LDLcholesterol at three time points [24]. The percentage of participants not meeting each of the ADA recommendations at the three time points (baseline, three, and six months) were: HbAlc > $\%(53 \mathrm{mmol} / \mathrm{mol})(55 \%, 47 \%, 45 \%)$, blood pressure $>130 / 80(73 \%, 77 \%, 75 \%)$, and LDL-cholesterol $(63 \%, 67 \%, 60 \%)$. glycemic control. Meanwhile having more than 10 years of disease, OAD plus insulin treatment, and doing minimal physical activity was associated with poor glycemic control. There was not a significant association between the 
Participants older than 65 were more likely to have good glycemic control (PR=0.59; 95\% CI: 0.44-0.78) than their younger counterparts. Similar results were found in other studies, for example in Mexico and the United States [27, 28], where a significant relationship between good glycemic control and an elderly population were found. Furthermore, the ACCADEMY study group[29] showed that patients older than 65 achieve the glycemic goal $\mathrm{HbA} 1 \mathrm{c}<7 \%$ (53 mmol/mol) more rapidly than their younger counterparts, with older patients achieving the recommended levels within 15 months compared to 21 months of treatment.

It has also been shown that the years of disease have a significant impact towards glycemic control, which may be due to decreased insulin production from decreased beta-cell function after 5 to 10 years of disease [30]. In agreement, our participants with a diagnosis of $\geq 10$ years were more likely to have a poor glycemic control. This is supported by a study conducted in Jordan [31], where those who had their diagnosis 10 or more years previously had increased odds of developing poor glycemic control ( $\mathrm{OR}=1.53$; 95\% CI: 1.09-2.17). In summary, these results strongly suggest that duration of disease has a greater impact on glycemic control than patient age.

Another variable associated with good glycemic control was marital status. In this study, being in a relationship was shown to have protective effects with regards to the HbA1c goals and consequently better prognosis. This is reinforced by several studies where they found that having a partner is associated with better adherence to treatment $[28,32,33]$ and decreased odds of poor glycemic control [31].

Participants with no pharmacological treatment had better glycemic control in comparison with OAD or OAD plus insulin. Similar results were reported in the Center for Disease Control and Prevention supplement [28]. This can be explained because use of insulin alone or insulin in combination with oral drugs is used to treat long-standing forms of the disease, whereas management without pharmacological treatment is used for milder form of the disease [28]. Ahmad et al. demonstrated that all pharmacological treatment patterns (monotherapy, combination of OAD, insulin and OAD plus insulin) were more likely - in varying degrees - to have poor glycemic control [34]. This may be associated with adverse effects and a lack of adherence to the treatment regimen.

Association of physical activity, through IPAQ score, showed that minimal physical activity was associated with poor glycemic control ( $\mathrm{PR}=1.34 ; 95 \%$ CI: 1.04-1.73) compared to HEPA active patients. Similar results were found by Abdel et al., who found a statistically significant association between patients with uncontrolled T2DM and lack of activity $(71.6 \%$ vs $28.4 \%$, p $<0.001)[35]$.

According to EATDMIII scale, 56.99\% patients with diabetes were adherent to non-pharmacological treatment. However, it was still beneath the rate of $66 \%$ found by Alayón et al. in Colombia [36]. It should be noted that they utilized a self-administered questionnaire SDSCA (summary of diabetes self-care activities) which does not take into account family support or community organization [36]. Both of these factors were analyzed with the EATDM III [20]. In Table 2, we illustrate that the median for EATDMIII scale was similar for the patients with good glycemic control and for the patients with poor glycemic control which suggests that glycemic control and adherence might be influenced by other factors such as knowledge of the disease [37], disease characteristics, environment, and intrapersonal and interpersonal factors [38]. 
242 Prevalence of depression in our patients with T2DM was 33.33\%, which is five times the prevalence of depression

243 reported in the general population (6.7\%) [39]. However, there was not a significant correlation between depression

244 and glycemic control in our sample. Some data tends to demonstrate a higher prevalence of depression in persons

245 with T2DM when compared to their diabetes-free counterparts, but the evidence is inconsistent [40, 41]. Some

246 longitudinal studies showed that distress can be linked specifically to diabetes and its management, but neither

247 clinical depression nor depressive symptoms seem to be associated with glycemic control [22, 40]. Several factors

248 including biochemical changes that are directly caused by diabetes, diabetes treatment, or distress associated with

249 living with this disease has to be studied in order to find an association. Although we did not find an association

250 between depression and glycemic control, this may be because the power of our sample (for this particular

251 association) was very low (28\%).

252 Factors significantly associated with poor glycemic control were not associated with LDL-cholesterol or blood 253 pressure, suggesting that there are different factors that we have not explored and could be associated.

\subsection{Limitations and strengths}

255

256

257

This study was small and localized to a single hospital in Peru. The small sample size and single site limits our generalizability and may have limited our scope of findings. Moreover, patients who participated in the study are representative of a low-income urban area, so we are unable to generalize the results to the whole population. The socio-economic characteristics of our population may have influenced rates of adherence, physical activity, and depression symptoms [42, 43].

Another limitation of this study is that currently, in addition to ADA recommendations, a patient-centered approach is promoted to individualize treatment plans taking into consideration life expectancy, disease duration, complications, comorbidities, hypoglycemia, and psychological status. Unfortunately, we do not have enough information to determine the adequate HbAlc level for each participant. Despite this limitation, this study is important and highlights a challenge to improve the health system for people with T2DM to achieve a better metabolic control, keeping in mind the necessary focus on individualization of the intensity of treatment and essential security aspects. Our findings can help to direct better management of patients with T2DM. We have shown that patients are not achieving the standards recommended by the ADA and now we can try to achieve them by targeting the significant factors including: increasing physical activity, protecting relationships with psychological couple therapy, rechecking diabetes medication, and enhancing adherence. Further studies should be conducted to determine the influence of lifestyle factors in management of T2DM.

\subsection{Conclusions}

The quality of control of HbA1c, LDL-cholesterol, and blood pressure was surprisingly low in patients with T2DM in this study. In comparison to similar studies, these levels are the lowest in the literature. Additionally, patients also exhibited low glycemic control. This situation cannot solely be explained by poor adherence, but it could be explained in combination with depression or low physical activity. Further studies are needed to fully understand this problem and until this is achieved, we cannot make the necessary recommendations to address this problem. 
277

278 Acknowledgments

279 The authors thank Valerie Paz-Soldán and Amy Powell for their valuable comments and review onto this article, and 280 Ray Ticse, Miguel Pinto, Mariela Florez, and Carmela Costta for their help in patient recruitment. 


\section{References}

1. Fauci A, Braunwald E, Kasper D, Hauser S, Longo D, Jameson J, Loscalzo J. Diabetes Mellitus. Harrison. Principios de Medicina Interna, 17 edición ed. México, D.F: McGraw-Hill Interamericana; 2009, p. 22752304.

2. Aschner P, Aguilar-Salinas C, Aguirre L, Franco L, Gagliardino JJ, de Lapertosa SG, Seclen S, Vinocour M. Diabetes in South and Central America: An update. Diabetes Res Clin Pract 2014; 103:238-43. doi:10.1016/j.diabres.2013.11.010.

3. Seclen SN, Rosas ME, Arias AJ, Huayta E, Medina CA. Prevalence of diabetes and impaired fasting glucose in Peru: report from PERUDIAB, a national urban population-based longitudinal study. BMJ Open Diabetes Res Care 2015;3:e000110. doi:10.1136/bmjdrc-2015-000110.

4. Huang ES, Laiteerapong N, John PM, Moffet HH, Karter AJ. Rates of complications and mortality in older patients with diabetes mellitus: the diabetes and aging study. JAMA Intern Med. 2014 Feb 1; 174(2):251-8. doi: 10.1001/jamainternmed.2013.12956.

5. Colosia AD, Palencia R, Khan S. Prevalence of hypertension and obesity in patients with type 2 diabetes mellitus in observational studies: a systematic literature review. Diabetes Metab Syndr Obes 2013; 6:32738. doi:10.2147/DMSO.S51325.

6. World Health Organization. Global Health Estimates: Deaths by Cause, Age, Sex and Country, 2000-2012. Geneva, WHO, 2014.

7. Schneiderman N, Llabre M, Cowie CC, Barnhart J, Carnethon M, Gallo LC, Giachello AL, Heiss G, Kaplan RC, LaVange LM, Teng Y, Villa-Caballero L, Avilés-Santa ML. Prevalence of Diabetes Among Hispanics/Latinos From Diverse Backgrounds: The Hispanic Community Health Study/Study of Latinos (HCHS/SOL). Diabetes Care 2014; 37:2233-9. doi:10.2337/dc13-2939

8. Lopez Stewart G, Tambascia M, Rosas Guzmán J, Etchegoyen F, Ortega Carrión J, Artemenko S. Control of type 2 diabetes mellitus among general practitioners in private practice in nine countries of Latin America. Rev Panam Salud Publica. 2007; 22(1): 12-20.

9. Brenes-Camacho G, Rosero-Bixby L. Metabolic control in a nationally representative diabetic elderly sample in Costa Rica: patients at community health centers vs. patients at other health care settings. $B M C$ Int Health Hum Rights 2008;8:5. doi:10.1186/1472-698X-8-5.

10. American Diabetes Association. Standards of Medical Care in Diabetes-2016.Diabetes Care. 2016; 39(1):S1-S112.

11. Westman EC, Yancy WS, Mavropoulos JC, Marquart M, McDuffie JR. The effect of a low-carbohydrate, ketogenic diet versus a low-glycemic index diet on glycemic control in type 2 diabetes mellitus. Nutr Metab (Lond) 2008;5:36. doi:10.1186/1743-7075-5-36.

12. Gonzales JS, Safren SA, Cagliero E, Wexler DJ, Delahanty L, Wittenberg E, Blais MA, Meigs JB, Grant RW.Depression, Self-Care, and Medication Adherence in Type 2 Diabetes, Diabetes Care. 2007 Sep; 30(9):2222-2227. 
13. Zuberi SI, Syed EU, Bhatti JA. Association of depression with treatment outcomes in Type 2 Diabetes Mellitus: A cross-sectional study from Karachi, Pakistan. BMC Psychiatry 2011;11:27. doi:10.1186/1471244X-11-27.

14. Stanković Z, Jašović-Gašić $M$, Zamaklar M. Psycho-social and clinical variables associated with depression in patients with type 2 diabetes. Psychiatr Danub 2011;23:34-44.

15. Oficina de Epidemiología y Salud Ambiental. MINSA:Análisis de la Situación de Salud del Hospital Cayetano Heredia.Lima,Perú.2014.

16. Simpson E, Pilote L. Quality of life after acute myocardial infarction: A comparison of diabetic versus nondiabetic acute myocardial infarction patients in Quebec acute care hospitals. Health Qual Life Outcomes. 2005; 3: 80. doi: $10.1186 / 1477-7525-3-80$

17. Resnick HE, Carter EA, Lindsay R, Henly SJ, Ness FK, Welty TK, Lee ET, Howard BV. Relation of lower-extremity amputation to all-cause and cardiovascular disease mortality in American Indians: the Strong Heart Study. Diabetes Care. 2004 Jun; 27(6):1286-93.

18. Handelsman Y, Bloomgarden ZT, Grunberger G, Umpierrez G, Zimmerman RS, Bailey TS, Blonde L, Bray GA, Cohen AJ, Dagogo-Jack S, Davidson JA, Einhorn D, Ganda OP, Garber AJ, Garvey WT, Henry RR, Hirsch IB, Horton ES, Hurley DL, Jellinger PS, Jovanovič L, Lebovitz HE, LeRoith D, Levy P, McGill JB, Mechanick JI, Mestman JH, Moghissi ES, Orzeck EA, Pessah-Pollack R, Rosenblit PD, Vinik AI, Wyne K, Zangeneh F. American association of clinical endocrinologists and american college of endocrinology - clinical practice guidelines for developing a diabetes mellitus comprehensive care plan 2015. Endocr Pract. 2015 Apr;21 Suppl 1:1-87. doi: 10.4158/EP15672.GL.

19. IPAQ Research Committee. International Physical Activity Questionnaire. http://www.ipaq.ki.se/ (accessed August 16 of 2015).

20. Villalobos-Pérez A, Brenes-Sáenz JC, Quirós-Morales D, León-Sanabria G. Características psicométricas de la escala de adherencia al tratamiento de la diabetes mellitus tipo II-VersiónIII. Acta Colombiana de Psicologia.2006; 9(2): 31-38.

21. Ruiz-Grosso P, Loret de Mola C, Vega-Dienstmaier JM, Arevalo JM, Chavez K, Vilela A, Lazo M, Huapaya J.Validation of the Spanish Center for Epidemiological Studies Depression and Zung Self-Rating Depression Scales: a comparative validation study. PLoS One 2012;7:e45413. doi:10.1371/journal.pone.0045413.

22. Crispin B,Robles MC,Bernabe A. Association between depression and glycemic control among type 2 diabetes patients in Lima, Peru. Asia Pac Psychiatry. Dec;7(4):419-26. doi: 10.1111/appy.12190.

23. Machado-Alba JE, Moncada-Escobar JC, Gaviria H. Quality and effectiveness of diabetes care for a group of patients in Colombia. Rev Panam Salud Publica 2009;26:529-35. doi:S1020-49892009001200008 [pii].

24. Menon AS, Ahluwalia AI. The ABC of diabetes. How many patients are able to achieve the goal laid down by American Diabetes Association? Med J Armed Forces India 2015;1:5-7. doi:10.1016/j.mjafi.2014.10.008. 
355

356

357

358

359

360

361

362

363

364

365

366

367

368

369

370

371

372

373

374

375

376

377

378

379

380

381

382

383

384

385

386

387

388

389

390

25. Gaede P, Lund-Andersen H, Parving H-H, Pedersen O. Effect of a multifactorial intervention on mortality in type 2 diabetes. N Engl J Med 2008;358:580-91. doi:10.1056/NEJMoa0706245.

26. Pinchevsky Y, Butkow N, Chirwa T, Raal FJ . Glycaemic, blood pressure and cholesterol control in 25629 diabetics. Cardiovasc J Afr 2015;26:188-92. doi:10.5830/CVJA-2015-050.

27. Flores-Hernández S, Saturno-Hernández PJ, Reyes-Morales H, Barrientos-Gutiérrez T, Villalpando S, Hernández-Ávila M. Quality of Diabetes Care: The Challenges of an Increasing Epidemic in Mexico. Results from Two National Health Surveys (2006 and 2012). PLoS One 2015;10:e133958. doi:10.1371/journal.pone.0133958.

28. Ali MK, McKeever Bullard K, Imperatore G, Barker L, Gregg EW, Centers for Disease Control and Prevention (CDC). Characteristics associated with poor glycemic control among adults with self-reported diagnosed diabetes--National Health and Nutrition Examination Survey, United States, 2007-2010. MMWR Morb Mortal Wkly Rep. 2012 Jun 15; 61 Suppl: 32-7.

29. Giorda CB, Cercone S, Nada E, ACCADEMY Study Group. Results of the adequacy of glycemic control in patients with type 2 Diabetes Mellitus treated with metformin monotherapy at maximal-tolerated dose. Endocrine. 2015 Aug 15 .doi: 10.1007/s12020-015-0692-9

30. Levy J, Alkinson AB, Bell PM, McCance DR, Hadden DR.Beta-cell deterioration determines the onset and rate of progression of secondary dietary failure in type 2 diabetes mellitus: the 10 year follows up of the Belfast diet study. Diabet Med. 1998; 15: 290-296.

31. Al-Akour NA, Khader YS, Alaoul AY. Glycemic control and its determinants among patients with type 2 diabetes mellitus attending a teaching hospital. J Diabetes Metab. 2011; 2(4): 1-5.

32. Thompson SJ, Auslander WF, White NH. Comparison of single-mother and two-parent families on metabolic control of children with diabetes. Diabetes Care 2001;24:234-8. doi:10.2337/diacare.24.2.234.

33. Harris MI, National H, Nutrition Examination S. Frequency of blood glucose monitoring in relation to glycemic control in patients with type 2 diabetes. Diabetes Care 2001;24:979-82.

34. Ahmad NS, Islahudin F, Paraidathathu T. Factors associated with good glycemic control among patients with type 2 diabetes mellitus. J Diabetes Investig 2014;5:563-9. doi:10.1111/jdi.12175.

35. Serour M, Alqhenaei H, Al-Saqabi S, Mustafa AR, Ben-Nakhi A.Cultural factors and patients' adherence to lifestyle measures. Br J Gen Pract 2007;57:291-5.

36. Alayón AN, Mosquera-Vásquez M. Adherencia al Tratamiento basado en Comportamientos en Pacientes Diabéticos Cartagena de Indias, Colombia. Rev Salud Pública 2008;10:777-87. doi:10.1590/S012400642008000500010.

37. Milla JN, Perez J, Rodriguez GM. Conocimientos sobre su enfermedad en pacientes con diabetes mellitus tipo 2 que acuden a hospitales generales. Rev Med Hered 2008;19:68-72

38. WHO. Adherence to long-term therapies. Who 2003:1-194.

39. Instituto Especializado de Salud Mental "Honorio Delgado - Hideyo Noguchi." Estudio epidemiologico metropolitano en salud mental 2002: Informe general. An Salud Ment 2002;XVIII:1-200 
391

392

393

394

395

396

397

398

399

400

401
40. Hamer M, Batty GD, Kivimaki M. Haemoglobin A1c, fasting glucose and future risk of depressive symptoms over 2 years follow up in the English Longitudinal Study of Ageing. Psychol Med. 2011 Sep; 41(9):1889-96. doi: 10.1017/S0033291711000079.

41. Fisher L, Mullan JT, Arean P, Glasgow RE, Hessler D, Masharani U . Diabetes distress but not clinical depression or depressive symptoms is associated with glycemic control in both cross-sectional and longitudinal analyses. Diabetes Care 2010;33:23-8. doi:10.2337/dc09-1238.

42. Results of the epidemiological surveillance of diabetes mellitus in hospitals in Peru, 2012. Rev Peru Med Exp Salud Publica. 2014;31(1):9-15.

43. Popkin B. The nutrition transition and obesity in the developing world. J Nutrition. 2001;131(3):871S873 S. 
Table 1.Characteristics of the study population( $\mathrm{N}=123)$

Variables

Age mean \pm SD

Age groups (\%)

Age $<65$ years

Age $\geq 65$ years

Gender (\%)

Female

Male

Marital Status (\%)

Single

Married

Living together

Divorced

Widowed

Years of disease $(\%)$

1-10 years

$\geq 10$ years

Treatment (\%)

No pharmacological treatment

OAD

Insulin

OAD plus insulin

HbA1c (\%)

HbA1c(\%) by ranges

$\mathrm{HbA} 1 \mathrm{c}<7 \%$

$\mathrm{HbA} 1 \mathrm{c}=7-8 \%$

$\mathrm{HbA} 1 \mathrm{c}=8-9 \%$

$\mathrm{HbA} 1 \mathrm{c}=9-10 \%$

$\mathrm{HbA} 1 \mathrm{c}>10 \%$

LDL(mg/dL), mean \pm SD

Blood pressure (mmHg), mean $(\%)$

Without hypertension

With hypertension

BMI, mean \pm SD

IPAQ

HEPA active

Minimally active

Inactive

EATDM-III

Depression
$\mathrm{N}(\%)$

61.84( \pm 11.10$)$

$73(59.35 \%)$

$50(40.65 \%)$

$81(65.85 \%)$

42(34.15\%)

$19(15.45 \%)$

$53(49.09 \%)$

$25(20.33 \%)$

$7(5.69 \%)$

19(15.45\%)

61(49.59\%)

$62(50.41 \%)$

$10(8.13 \%)$

$74(60.16 \%)$

$8(6.50 \%)$

31(25.20\%)

$8.23 \pm 2.19$

$43(35.83 \%)$

23(19.17\%)

$22(18.33 \%)$

$9(7.5 \%)$

23(19.17\%)

$107.61 \pm 39.66$

$77(62.60 \%)$

$46(37.40 \%)$

$28.5 \pm 4.71$

$67(56.30 \%)$

25(21.01\%)

27(22.69\%)

$56.69 \pm 11.28$ 
Yes

$41(33.33 \%)$

No

HbA1c: Glycosylated hemoglobin

BMI:Body mass index

IPAQ:International Physical Activity Questionnaire

OAD:Oral antidiabetics

EATDM-III(Escala de adherencia al tratamiento de la diabetes mellitus tipo II) 
Table 2. Characteristics of the study population according to glycemic control

\begin{tabular}{|c|c|c|c|}
\hline & Good glycemic control (n=38) & $\begin{array}{l}\text { Poor glycemic control } \\
(\mathrm{n}=82)\end{array}$ & $\begin{array}{c}\mathrm{p}- \\
\text { value }\end{array}$ \\
\hline \multicolumn{4}{|l|}{ Demographics } \\
\hline Age \pm SD & $64.80 \pm 10.4$ & $60.47 \pm 11.2$ & \\
\hline Age per range $(\%)$ & & & 0.004 \\
\hline Age $<65$ years & $16(21.92 \%)$ & $57(78.08 \%)$ & \\
\hline Age $\geq 65$ years & $22(46.81 \%)$ & $25(53.19 \%)$ & \\
\hline Gender $(\%)$ & & & 0.674 \\
\hline Female & $24(30.38 \%)$ & $55(69.62 \%)$ & \\
\hline Male & $14(34.15 \%)$ & $27(65.85 \%)$ & \\
\hline Marital status(\%) & & & 0.139 \\
\hline Without couple & $10(23.26 \%)$ & $33(76.74 \%)$ & \\
\hline With couple & $28(36.36 \%)$ & $49(63.64 \%)$ & \\
\hline \multicolumn{4}{|l|}{ Clinical } \\
\hline $\mathbf{B M I} \pm$ SD & $27.7 \pm 4.52$ & $28.87 \pm 4.78$ & \\
\hline Years of disease $(\%)$ & & & 0.013 \\
\hline $1-10$ years & $25(42.37 \%)$ & $34(57.63 \%)$ & \\
\hline$\geq 10$ years & $13(21.31 \%)$ & $48(78.59 \%)$ & \\
\hline Treatment $(\%)$ & & & $<0.001$ \\
\hline No pharmacological treatment & $7(70 \%)$ & $3(30 \%)$ & \\
\hline $\mathrm{OAD}$ & $28(38.89 \%)$ & $44(61.11 \%)$ & \\
\hline Insulin & $2(25 \%)$ & $6(75 \%)$ & \\
\hline OAD plus Insulin & $1(3.33 \%)$ & $29(96.67 \%)$ & \\
\hline \multicolumn{4}{|l|}{ Complications $(\%)$} \\
\hline Microvascular & & & 0.593 \\
\hline Yes & $12(28.57 \%)$ & $30(71.43 \%)$ & \\
\hline No & $26(33.33 \%)$ & $52(66.67 \%)$ & \\
\hline Macrovascular & & & 0.597 \\
\hline Yes & $7(36.84 \%)$ & $12(63.16 \%)$ & \\
\hline No & $31(30.69 \%)$ & $70(69.319 \%)$ & \\
\hline \multicolumn{4}{|l|}{ Lifestyle } \\
\hline IPAQ(\%) & & & 0.143 \\
\hline HEPA active & $25(37.31 \%)$ & $42(62.69 \%)$ & \\
\hline Minimally active & $4(16 \%)$ & $21(84 \%)$ & \\
\hline Inactive & $8(29.63 \%)$ & $19(70.37 \%)$ & \\
\hline EATDM-III \pm SD & $57.26 \pm 11.81$ & $56.42 \pm 11.10$ & \\
\hline \multicolumn{4}{|l|}{ Comorbidities } \\
\hline $\operatorname{Depression}(\%)$ & & & 0.684 \\
\hline Yes & $12(29.27 \%)$ & $29(70.73 \%)$ & \\
\hline No & $26(32.91 \%)$ & $53(67.09 \%)$ & \\
\hline
\end{tabular}

BMI:Body mass index

IPAQ:International Physical Activity Questionnaire

OAD:Oral antidiabetics

EATDM-III(Escala de adherencia al tratamiento de la diabetes mellitus tipo II) 
Table 3. Factors associated with glycemic control, LDL cholesterol and blood pressure

\section{Glycemic control}

Crude model Multivariable model*

PR ( 95\% IC)

\section{Gender}

Female

Male

Age

Age $<65$ years

Age $\geq 65$ years

\section{Marital status}

Without couple

With couple

Years of diasease

1- 10 years

$\geq 10$ years

\section{Treatment}

No pharmacological treatment

OAD

Insulin

OAD plus insulin

\section{Complications}

No complications

At least 1 complication

\section{IPAQ}

HEPA active

Minimally active

Inactive

Depression

PR (95\%IC)

1(Reference)

1(Reference)

0.95(0.73-1.23)

1.07(0.84-1.36)

1(Reference)

0.68(0.51-0.92)

1(Reference)

0.59(0.44-0.78)

0.83(0.65-1.05)

1(Reference)

0.74(0.59-0.92)

1(Reference)

1.37(1.06-1.76)

1 (Reference)

1.34(1.05-1.71)

1 (Reference)

2.04(0.77-5.37)

2.5(0.89-7.02)

3.22(1.24-8.36)

\section{1(Reference)}

0.98(0.76-1.25)

1(Reference)

1.34(1.04-1.73)

1.12(0.83-1.53)

\section{1(Reference) \\ $1.75(0.70-4.38)$ \\ $1.70(0.62-4.65)$ \\ 2.57(1.05-6.32)}

1(Reference)

0.80(0.62-1.03)

1(Reference)

1.63(1.23-2.15)

1.31(0.98-1.75)
LDL cholesterol

Crude model Multivariable model*

PR ( 95\% IC)

PR ( 95\% IC)

1(Reference)

1.00(0.74-1.36)

1 (Reference)

\section{1(Reference)}

0.91(0.67-1.24)

\section{1 (Reference)}

0.95(0.71-1.28)

1(Reference)

1.03(0.74-1.43)

1 (Reference)

0.94(0.71-1.26)

1 (Reference)

0.85(0.62-1.17)

1 (Reference)

0.97(0.56-1.68)

$1.06(0.59-1.88)$

1.13(0.85-1.51)

1(Reference)

0.89(0.60-1.33)

$0.95(0.66-1.36)$
Blood pressure

Crude model Multivariable model**

PR ( 95\% IC)

PR ( 95\% IC)

\section{1 (Reference)}

$1.01(0.62-1.64)$

$1($ Reference $)$
$1.06(0.66-1.72)$

1 (Reference)

1(Reference)

$1.61(0.99-2.60)$

.36(0.86-2.15)

1(Reference)

(Reference)

$1.32(0.80-2.19)$

$1.12(0.68-1.84)$

1(Reference)

1(Reference)

$0.85(0.53-1.34)$
1(Reference)

$0.99(0.58-1.71)$

$1.29(0.65-2.56)$

$1.13(0.62-2.04)$

1(Reference)

$1.23(0.89-1.69)$

\section{1(Reference)}

1.01(0.45-2.27)

0.94(0.29-3.05)

0.75(0.29-1.92)

1(Reference)

0.80(0.49-1.31)

$\begin{array}{cc}1 \text { (Reference) } & 1 \text { (Reference) } \\ 0.91(0.61-1.37) & 0.86(0.45-1.65) \\ 0.93(0.64-1.34) & 1.19(0.70-2.02)\end{array}$

$-$ 
No

Yes

$\begin{array}{ccccc}1 \text { (Reference) } & 1 \text { (Reference) } & 1 \text { (Reference) } & 1 \text { (Reference) } & 1 \text { (Reference) } \\ 1.05(0.82-1.36) & 1.17(0.94-1.45) & 1.00(0.74-1.36) & 0.93(0.67-1.27) & 1.54(0.98-2.42) \\ 1.00(0.99-1.01) & 1.00(1.00-1.02) & 1.00(0.98-1.01) & 0.99(0.98-1.01) & 0.98(0.96-1.01)\end{array}$

EATDM-III $1.00(0.99-1.01)$

$0.99(0.98-1.01)$

* Adjusted model for gender, marital status, years of disease, treatment, complications, IPAQ, depression and EATDM-III

** Adjusted model for gender,age, marital status, years of disease and EATDM-III

IPAQ:International Physical Activity Questionnaire

OAD:Oral antidiabetics

EATDM-III(Escala de adherencia al tratamiento de la diabetes mellitus tipo II) 